\title{
PENGARUH KONTEKS TEKNOLOGI, LINGKUNGAN, ORGANISASI DALAM PENGGUNAAN MEDIA SOSIAL DAN DAMPAKNYA PADA KINERJA USAHA BAKERY
}

\author{
Jonathan Anastasius dan Lydiawati Soelaiman \\ ${ }^{1}$ Program Studi Sarjana Manajemen, Universitas Tarumanagara \\ Email: jonathan.115160372@stu.untar.ac.id \\ ${ }^{2}$ Program Studi Sarjana Manajemen, Universitas Tarumanagara \\ Email: lydiawatis@fe.untar.ac.id
}

\begin{abstract}
The purpose of this study is to determine the effect of Technological Context, Environmental Context, Organizational Context on Social Media Usage of MSME Bakery in Jakarta and analyzing the influence of Social Media Usage on Business Performance of UMKM Bakery in Jakarta.The sample used in this study amounted to 48 respondents who have a bakery in Jakarta. The results show that there is a significant influence between Environmental Context on Social Media Usage and there is a significant effect on Social Media Usage on Business Performance. There is no significant effect between Techological Context and Organizational Context on Social Media Usage.
\end{abstract}

Keywords: Technological Context, Environmental Context, Organizational Context, Social Media Usage and Business Performance

Abstrak: Tujuan dari penelitian ini adalah untuk mengetahui pengaruh Konteks Teknologi, Konteks Lingkungan dan Konteks Organisasi dalam Penggunaan Media Sosial pada usaha Bakery di Jakarta dan mengetahui pengaruh Penggunaan Media Sosial terhadap Performa Bisnis usaha Bakery di Jakarta. Sampel yang digunakan dalam penelitian ini berjumlah 48 orang responden yang memiliki bakery di Jakarta. Hasil menunjukkan terdapat pengaruh signifikan antara Konteks Lingkungan terhadap Penggunaan Media Sosial dan terdapat pengaruh signifikan terhadap Penggunaan Media Sosial terhadap Performa Bisnis. Tetapi tidak terdapat pengaruh yang signifikan antara Konteks Teknologi dan Konteks Organisasi terhadap Penggunaan Media Sosial.

Kata Kunci: Konteks Teknologi, Konteks Lingkungan, Konteks Organisasi, Penggunaan Media Sosial dan Performa Bisnis

\section{PENDAHULUAN}

Media sosial sangat membantu perkembangan bisnis khususnya Usaha Mikro Kecil Menengah (UMKM). Media sosial telah menjadi media yang sangat efektif dan sangat berguna untuk menyebarkan informasi dan mempengaruhi orang untuk berbelanja online. Pada saat ini UMKM berlomba-lomba untuk memasarkan berbagai jenis produknya yang tidak kalah kualitasnya dengan produk perusahaan besar. Persaingan yang ketat di pasar membuat para pebisnis harus saling bersaing untuk menjadi yang terbaik di pasar. Untuk itu, peran media sosial 
sangat penting bagi UMKM dalam membantu memperkenalkan produknya kepada konsumen dengan segala keterbatasan yang dimiliki oleh UMKM.

Hal ini juga didukung oleh pernyataan Wakil Presiden Indonesia, Bapak Ma'ruf Amin yang menegaskan pentingnya perluasan akses pasar bagi para pelaku Usaha Mikro Kecil Menengah (UMKM) dengan melakukan pemasaran digital seperti menggandeng para perusahaan e-commerce. Hal ini sangat perlu dilakukan mengingat kontribusi UMKM pada pertumbuhan ekonomi Indonesia begitu besar dan sangat krusial karena mencakup 99\% jumlah unit usaha di Indonesia (Akbar, 2020).

Salah satu bisnis UMKM yang berkembang terutama dalam masa pandemi ini adalah usaha kuliner, termasuk di dalamnya adalah usaha makanan ringan. Toko roti (bakery) merupakan bagian dari industri pengolahan makanan yang menggunakan tepung terigu sebagai bahan baku utama dalam proses produksinya. Dalam ilmu pangan, roti dibagi menjadi produk bakery yang terdiri dari kue, donat, biskuit, roti gulung, biscuit, pai dan lainnya. roti hanya dikonsumsi untuk kelompok orang tertentu, sebatas sarapan pagi. Kemudian berkembang menjadi pola makan penduduk perkotaan yang sibuk. Sekarang, roti biasanya digunakan untuk sarapan pagi, snack dan makanan siap santap saat dibutuhkan. Keberadaan roti sudah mulai disambut baik oleh semua lapisan masyarakat, yang menjadikan peluang bisnis industri roti semakin luas.

Melihat pesatnya perkembangan toko roti / bakery di Indonesia terutama di Jakarta, maka perlu menampilkan produk-produk baru yang lebih inovatif agar lebih menarik. Salah satunya dengan membuat produk bakery dengan variasi yang berbeda-beda sehingga dapat menarik dan memenuhi kebutuhan pelanggan. Jika hal ini dapat dipenuhi, maka secara tidak langsung maka konsumen akan membantu promosi produk itu sendiri tanpa diminta. Hal ini dirasakan oleh pemilik Disini Bakery yang menyatakan bahwa produknya meningkat 2 kali lipat karena banyak anak muda yang berfoto dan meng-upload produknya melalui media sosial (Newswire, 2012).

Oleh karena itu, tidak dapat dipungkiri dengan berkembangnya teknologi maka fungsifungsi yang dapat digunakan di media sosial juga akan memberikan keuntungan yang lebih besar bagi para pebisnis UMKM. Menurut Basole (2005) konteks teknologi, berfokus pada karakteristik teknologi yang dipertimbangkan seperti media sosial. Mansyur (2016) menyatakan bahwa globalisasi yang semakin pesat, kecepatan perkembangan teknologi informasi juga berdampak pada peningkatan penggunaan media sosial di masyarakat.

Selain itu, konteks organisasi juga berdampak terhadap penggunaan media sosial. Menurut Tornatzky dan Fleischer (1990) konteks organisasi didefinisikan dalam istilah karakteristik deskriptif, seperti ukuran perusahaan, sentralisasi atau formalisasi, proses komunikasi (dengan pelanggan atau karyawan), dan struktur manajemen. Menurut Osch dan Coursaris (2013) terdapat kaitan yang positif dan signifikan antara Konteks Organisasi dengan Penggunaan Sosial Media, beliau meneliti bahwa terdapat lima jenis kegiatan organisasi yang didukung oleh media sosial, empat diantaranya adalah kegiatan internal yaitu community building, knowledge management / sharing, inovasi, dan pembentukan kebijakan, dan satu kegiatan eksternal yaitu branding / pemasaran.

Dalam hal konteks lingkungan, menurut Köse dan Sert (2015) efek dari konteks lingkungan pada media sosial adalah adanya penggunaan pendekatan, metode, atau teknologi yang berbeda untuk memungkinkan orang - pengguna mengalami komunikasi interaktif dan berbagai cara berbagi, berkreasi, dan juga bertukar informasi. Menurut Rapali dan Soelaiman (2019) lingkungan eksternal juga berpengaruh terhadap keberhasilan atau kegagalan dalam sebuah perusahaan, karena elemen-elemen yang ada di dalam lingkungan tersebut mendorong dan dapat juga menghambat aktifitas bisnis 
Para pebisnis mulai mengapresiasi fitur dari media sosial untuk dapat menciptakan peluang baru dalam meningkatkan performa. Hogan dan Strasburger (2018) juga menemukan hubungan yang positif dan signifikan antara penggunaan media sosial dengan peforma bisnis yaitu media sosial membantu perusahaan untuk menjangkau pelanggan baru terutama yang berusia muda dengan lebih mudah karena saluran komunikasi ini semakin populer di kalangan generasi muda.

\section{KAJIAN TEORI}

\section{Definisi Variabel}

Menurut Soares-Aguiar dan Palma-dos-Reis (2008) teknologi didefinisikan sebagai "In terms of the knowledge and skills needed to apply certain technology, it is technical capabilities that include technical infrastructure and information technology (IT) resources." Artinya, dalam hal pengetahuan dan keterampilan yang dibutuhkan untuk menerapkan teknologi tertentu, adalah kemampuan teknis yang mencakup infrastruktur teknis dan sumber daya teknologi informasi (TI).

Menurut Rusu dan Avasilcai (2015) "the organizational context represented by the internal environment which influences directly employees' behaviors and attitudes, comprises the following factors: the organizational culture, employees relations climate, the individuals involved, the organizational structure, the organization size, the technology of the organization and key activities, the work practices, the type of business (according to the object of activity), the age or maturity of the organization." Artinya, konteks organisasi diwakili oleh lingkungan internal yang secara langsung mempengaruhi perilaku dan sikap karyawan, meliputi faktorfaktor berikut: budaya organisasi, suasana hubungan karyawan, individu yang terlibat, struktur organisasi, skala organisasi, teknologi organisasi dan kegiatan utama, praktik kerja, jenis usaha (menurut objek kegiatan), usia atau kematangan organisasi.

Menurut Soelaiman dan Utami (2021) social media adalah sekelompok aplikasi berbasis internet yang dikembangkan agar dapat bermanfaat untuk individu maupun komunitas, dan dapat menghasilkan interaksi serta penyebaran informasi yang bermanfaat bagi perusahaan dan juga konsumen.

Menurut Barney (1991) Performa Bisnis didefinisikan sebagai "The resource and capabilitiesbased view argues that a company's business performance is determined by its effectiveness in converting resources (eg assets, knowledge, processes) into capabilities (eg customer relationships; sales capabilities, reputation placement) to achieve competitive advantage." Artinya, pandangan berdasarkan sumber daya dan kapabilitas percaya bahwa Performa Bisnis suatu perusahaan bergantung pada kemampuannya untuk mengubah sumber daya (seperti aset, pengetahuan, dan proses) menjadi kapabilitas (seperti hubungan pelanggan, kapabilitas penjualan, penempatan reputasi) untuk mencapai efektivitas dan keunggulan kompetitif.

\section{Kaitan Konteks Teknologi dengan Penggunaan Media Sosial}

Menurut Hogan dan Strasburger (2018), ada pengaruh yang positif dan signifikan antara Konteks Teknologi dan Media Sosial sebab di dunia bisnis, media sosial menyelinap masuk tanpa diketahui, awalnya memungkinkan perusahaan untuk membuat fanpages dan me-posting berita, foto, dan video, terutama untuk tujuan membangun gambar. Seiring teknologi berkembang, perusahaan mulai menghargai keunggulan khusus komunikasi web dengan pelanggan serta penerapan alat ini untuk meningkatkan jangkauan produk/ layanan mereka dan untuk melibatkan pelanggan dalam pengembangan dan pengujian produk / layanan baru. 


\section{Kaitan Konteks Lingkungan dengan Penggunaan Media Sosial}

Menurut Köse dan Sert (2015) terdapat pengaruh yang positif dan signifikan antara Konteks lingkungan dengan Penggunaan Media Sosial, mereka meneliti bahwa efek dari konteks lingkungan pada media sosial adalah adanya penggunaan pendekatan, metode, atau teknologi yang berbeda untuk memungkinkan orang - pengguna mengalami komunikasi interaktif dan berbagai cara berbagi, berkreasi, dan juga bertukar informasi.

\section{Kaitan Konteks Organisasi dengan Penggunaan Media Sosial}

Menurut Osch dan Coursaris (2013) terdapat kaitan yang positif dan signifikan antara Konteks Organisasi dengan Penggunaan Sosial Media, beliau meneliti bahwa terdapat lima jenis kegiatan organisasi yang didukung oleh media sosial, empat diantaranya adalah kegiatan internal yaitu community building, knowledge management / sharing, inovasi, dan pembentukan kebijakan, dan satu kegiatan eksternal yaitu branding / pemasaran.

\section{Kaitan Penggunaan Media Sosial dengan Performa Bisnis}

Hogan dan Strasburger (2018) juga menemukan hubungan yang positif dan signifikan antara Penggunaan Media Sosial dengan Peforma Bisnis, mereka mengungkapkan bahwa media sosial membantu perusahaan untuk menjangkau pelanggan baru (terutama yang berusia muda) dengan lebih mudah karena saluran komunikasi ini semakin populer di kalangan generasi muda. Selain itu, pelatihan berbasis web, proyek berbasis tim, distribusi pembaruan tentang rencana dan aktivitas kepada karyawan, mencari penawaran baru dan verifikasi informasi selama perekrutan staf sangat memengaruhi performa bisnis suatu perusahaan.

Selain itu, Hogan dan Strasburger (2018) juga menjelaskan bahwa, penerapan media sosial yang paling utama dalam bisnis adalah dengan menggunakannya untuk berbagai macam kegiatan promosi. Awalnya, aktivitas tersebut terdiri dari menjaga hubungan yang baik dengan pelanggan dan mempromosikan merek, perusahaan, atau produk. Selanjutnya, pemasar mulai mengapresiasi fitur lain dari media sosial, yaitu kemungkinan untuk melibatkan pelanggan dalam mengembangkan/ membentuk produk baru. Ini juga menciptakan peluang baru untuk meningkatkan performa bisnis bidang-bidang usaha.

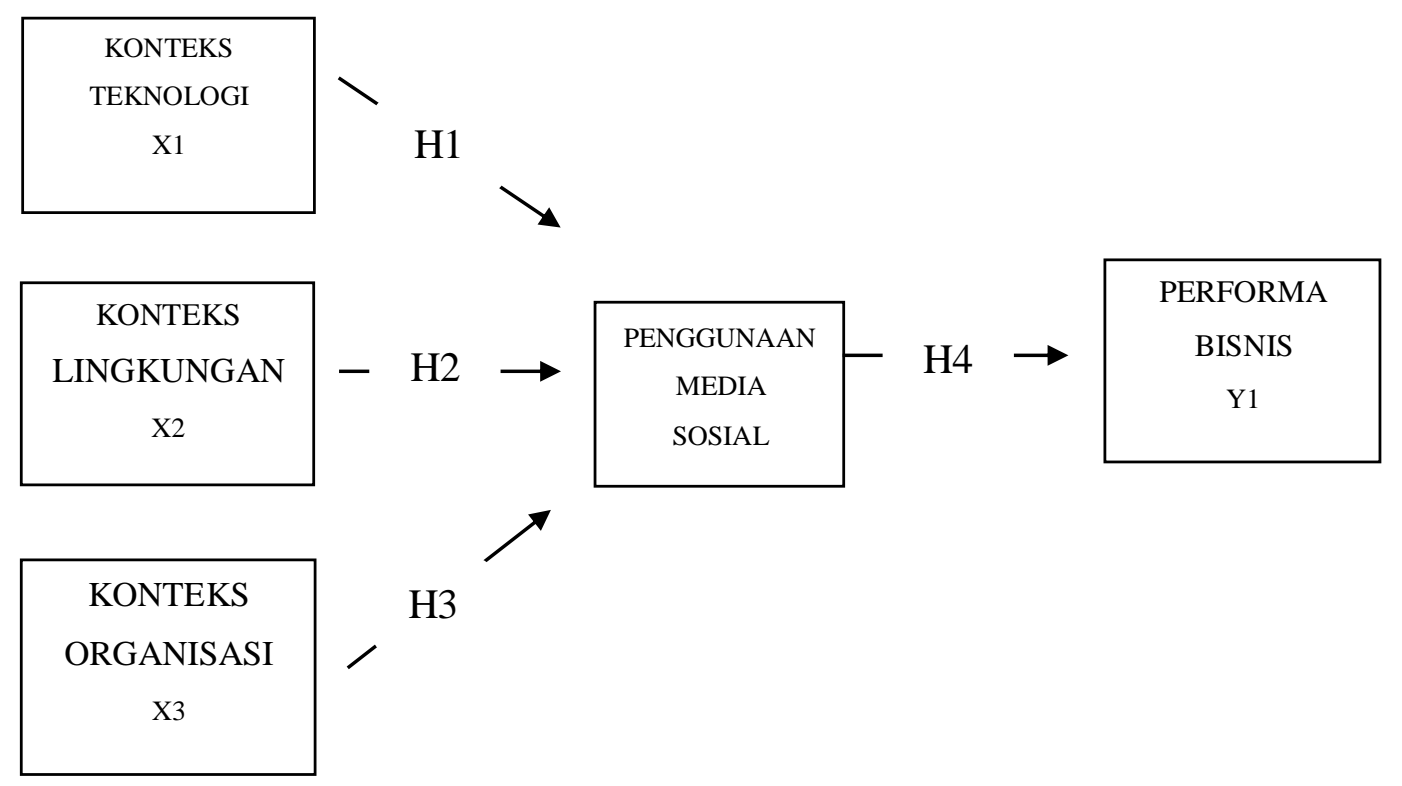

Gambar 1. Model Penelitian 
Berdasakan kerangka pemikiran di atas, hipotesis yang di pakai dalam penelitian ini adalah sebagai berikut:

H1: Terdapat pengaruh positif dan signifikan antara Konteks Teknologi terhadap Penggunaan Media Sosial.

H2: Terdapat pengaruh positif dan signifikan antara Konteks Lingkungan terhadap Penggunaan Media Sosial.

H3: Terdapat pengaruh positif dan signifikan antara Konteks Organisasi terhadap Penggunaan Media Sosial.

H4: Terdapat pengaruh positif dan signifikan antara Penggunaan Media Sosial terhadap Performa Bisnis

\section{METODELOGI}

Dalam penelitian ini digunakan metode deskriptif kuantitatif. Dari populasi yang ada, teknik pengambilan sampel yang akan digunakan dalam penelitian ini adalah teknik Nonprobability Sampling. Jenis sampel yang digunakan pada teknik Nonprobability Sampling, yaitu judgemental sampling dengan memanfaatkan media elektronik yaitu Google Form sebagai media penyebaran. penelitian ini menggunakan jumlah sampel yang akan diambil sebanyak 48 responden yang memiliki usaha Bakery di Jakarta, sehingga sampel penelitian yang digunakan dalam penelitian ini terdiri dari seluruh pengusaha yang memiliki usaha Bakery di Jakarta.

Variabel dalam penelitian ini disusun dengan skala interval dengan indikator pengukuran variabel sebagai berikut:

\section{Hasil Uji Validitas}

Uji validitas yang digunakan dalam penelitian ini adalah analisis validitas konvergen, dengan nilai AVE $\geq 0,50$ dan factor loading $>0,70$ dan validitas diskriminan, yaitu kriteria FornellLarcker dan nilai cross loading (Hair Jr et al., 2014).

Tabel 1. Hasil Analisis Average Variance Extracted

\begin{tabular}{c|c|c|c}
\hline Variable & AVE & Nilai Kritis & Keterangan \\
\hline Konteks teknologi & 0.663 & & \\
\hline Konteks Lingkungan & 0.747 & & \\
\hline Konteks Organisasi & 0.665 & $>0,5$ & Valid \\
\hline Penggunaan Media Sosial & 0.753 & & \\
\hline Performa Bisnis & 0.741 & & \\
\hline
\end{tabular}

*Sumber: olahan data SmartPLS 3.0

Berdasarkan tabel Average Variance Extracted semua variabel bernilai > 0,5, sehingga variabel valid dan dapat dilakukan pengujian olah data selanjutnya

\section{Hasil Uji Hipotesis}

Berdasarkan dari hasil pengujian koefisien determinasi yang telah dipaparkan pada tabel 4.10, Nilai dari R-Square sebesar 0.845 menjelaskan bahwa besar pengaruh pengambilan Konteks Teknologi, Konteks Lingkungan, Konteks Organisasi, terhadap Penggunaan Media Sosial ialah sebesar $84,5 \%$, sedangkan sisanya sebesar $15,5 \%$ dijelaskan oleh variable lain.Dan nilai dari R- 
Square sebesar 0.880 menjelaskan bahwa besar pengaruh pengambilan Konteks Teknologi, Konteks Lingkungan, Konteks Organisasi, dan Penggunaan Media Sosial terhadap Performa Bisnis ialah sebesar $88 \%$, sedangkan sisanya sebesar $12 \%$ dijelaskan oleh variable lain.

Tabel 2. Hasil Uji Hipotesis

\begin{tabular}{c|c|c|c|c|c}
\hline & Hipotesis & $\begin{array}{c}\text { Original } \\
\text { Sample }\end{array}$ & T Statistics & P Values & Kesimpulan \\
\hline H1 & $\begin{array}{c}\text { Konteks Teknologi -> Penggunaan } \\
\text { Media Sosial }\end{array}$ & 0.036 & 0.323 & 0.747 & $\begin{array}{c}\text { Tidak } \\
\text { Signifikan }\end{array}$ \\
\hline H2 & $\begin{array}{c}\text { Konteks Lingkungan -> } \\
\text { Penggunaan Media Sosial }\end{array}$ & 0.706 & 4.697 & 0.000 & Signifikan \\
\hline H3 & $\begin{array}{c}\text { Konteks Organisasi-> Penggunaan } \\
\text { Media Sosial }\end{array}$ & 0.206 & 1.591 & 0.112 & $\begin{array}{c}\text { Tidak } \\
\text { Signifikan }\end{array}$ \\
\hline H4 & $\begin{array}{c}\text { Pengunaan Media Sosial -> } \\
\text { Performa Bisnis }\end{array}$ & 0.938 & 30.937 & 0.000 & Signifikan \\
\hline
\end{tabular}

Berdasarkan Tabel 2 dapat ditarik kesimpulan bahwa variabel Konteks Lingkungan, dan Penggunaan Media Sosial berpengaruh secara signifikan, dimana masing-masing nilai t-statistic dari setiap variabel $>1,96$ dan nilai p-value dari masing-masing variabel $<0,05$ tetapi tidak dengan variable Konteks Teknologi dan Konteks Organisasi yang mempunyai nilai t-statistic $<1,96$ dan nilai p-value >0,05 yang berarti Konteks Teknologi dan Konteks Organisasi tidak berpengaruh secara signifikan terhadap Penggunaan Media Sosial.

Tabel 3. Outer Loading Factor

\begin{tabular}{|c|c|c|c|}
\hline \multicolumn{2}{|c|}{ Hasil } & Nilai Kritis & Keterangan \\
\hline \multicolumn{2}{|c|}{ Outer Model } & \multirow{20}{*}{$>0,5$} & \\
\hline Indikator & Loading & & \\
\hline BP1 & 0.895 & & Valid \\
\hline $\mathrm{BP} 2$ & 0.799 & & Valid \\
\hline BP3 & 0.875 & & Valid \\
\hline $\mathrm{BP} 4$ & 0.900 & & Valid \\
\hline BP5 & 0.924 & & Valid \\
\hline BP6 & 0.843 & & Valid \\
\hline $\mathrm{BP7}$ & 0.747 & & Valid \\
\hline BP8 & 0.890 & & Valid \\
\hline EC1 & 0.908 & & Valid \\
\hline $\mathrm{EC} 2$ & 0.889 & & Valid \\
\hline EC3 & 0.826 & & Valid \\
\hline EC4 & 0.832 & & Valid \\
\hline OC1 & 0.874 & & Valid \\
\hline $\mathrm{OC} 2$ & 0.865 & & Valid \\
\hline OC3 & 0.744 & & Valid \\
\hline $\mathrm{OC} 4$ & 0.734 & & Valid \\
\hline OC5 & 0.850 & & Valid \\
\hline SMU1 & 0.914 & & Valid \\
\hline
\end{tabular}




\begin{tabular}{c|c|c} 
SMU2 & 0.831 \\
\hline SMU3 & 0.820 \\
\hline SMU4 & 0.902 & Valid \\
\hline TC1 & 0.840 & Valid \\
\hline TC2 & 0.653 & Valid \\
\hline TC3 & 0.843 & Valid \\
\hline TC4 & 0.829 \\
\hline TC5 & 0.886 & Valid \\
\hline & & Valid \\
\hline & & Valid \\
\hline
\end{tabular}

Berdasarkan hasil data yang disajikan di tabel 3, diketahui bahwa nilai tertinggi berada di BP5, yaitu variabel Performa Bisnis sebesar 0.924, dan nilai terendah berada di TC2, yaitu variabel adopsi Konteks Teknologi sebesar 0,653.

Tabel 4. Hasil Uji Reliabilitas

\begin{tabular}{c|c|c|c|c}
\hline Variable & $\begin{array}{c}\text { Cronbach's } \\
\text { Alpha }\end{array}$ & $\begin{array}{c}\text { Composit } \\
\text { Reliability }\end{array}$ & $\begin{array}{c}\text { Nilai } \\
\text { Kritis }\end{array}$ & \multirow{2}{*}{ Keterangan } \\
\hline Konteks Teknologi & 0.872 & 0.907 & & \multirow{2}{*}{$>0,6$} \\
\hline Konteks Lingkungan & 0.887 & 0.922 & Reliabel \\
\hline Konteks Organisasi & 0.875 & 0.908 & & \\
\hline Penggunaan Media Sosial & 0.890 & 0.924 & & \\
\hline
\end{tabular}

\section{Hasil Uji Reliabilitas}

Tabel diatas menunjukkan bahwa secara keseluruhan nilai yang dihasilkan baik dengan pendekatan Cronbach alpha's maupun composite reliability adalah lebih besar dari 0.6. sehingga dapat disimpulkan bahwa data yang digunakan dalam penelitian ini adalah reliabel.

\section{HASIL DAN PEMBAHASAN}

Dalam penelitian ini melibatkan 48 orang responden yang memiliki Bakery di Jakarta. Penelitian ini mempunyai karakteristik responden menurut jenis kelamin, responden wanita mendominasi dalam penelitian ini yaitu sebanyak 37 orang wanita $(77,1 \%)$. Dalam penelitian ini 48 orang responden memiliki karakteristik usia $>35$ tahun yang mendominasi dalam penelitian ini yaitu sebanyak 16 orang $(33,3 \%)$. Karakteristik penelitian selanjutnya didominasi oleh pelaku usaha yang berdomisili di Jakarta barat sebanyak 22 orang (45.8\%).Dan terakhir karakteristik subjek penelitian berdasarkan lama usaha lebih dari 3 tahun dengan jumlah responden terbanyak sebanyak 20 orang (41.7\%).

Tabel 5. Hasil dari Uji Coefficient of Determination $\left(\mathbf{R}^{2}\right)$

\begin{tabular}{c|c}
\hline Variabel & R-Square \\
\hline Penggunaan Media Sosial & 0.845 \\
\hline Performa Bisnis & 0.880 \\
\hline
\end{tabular}


Nilai dari R-Square sebesar 0.845 menjelaskan bahwa besar pengaruh pengambilan Konteks Teknologi, Konteks Lingkungan, Konteks Organisasi, terhadap Penggunaan Media Sosial ialah sebesar $84,5 \%$, sedangkan sisanya sebesar $15,5 \%$ dijelaskan oleh variable lain.Dan nilai dari RSquare sebesar 0.880 menjelaskan bahwa besar pengaruh pengambilan Konteks Teknologi, Konteks Lingkungan, Konteks Organisasi, dan Penggunaan Media Sosial terhadap Performa Bisnis ialah sebesar $88 \%$, sedangkan sisanya sebesar $12 \%$ dijelaskan oleh variable lain.

Tabel 6. Hasil Predictive Relevance $\left(Q^{2}\right)$

\begin{tabular}{c|c}
\hline Variabel & Q-Square \\
\hline Penggunaan Media Sosial & 0,615 \\
\hline Performa Bisnis & 0,633 \\
\hline
\end{tabular}

Berdasarkan dari hasil pengujian Predictive Relevance yang telah dipaparkan, nilai dari QSquare sebesar 0,615 menjelaskan bahwa pengaruh Konteks teknologi, Konteks Lingkungan, Konteks Organisasi terhadap media sosial yaitu sebesar 61,5\%.Dan nilai dari Q-Square sebesar 0,633 menjelaskan bahwa pengaruh Konteks teknologi, Konteks Lingkungan, Konteks Organisasi, dan Penggunaan Media Sosial terhadap Performa Bisnis yaitu sebesar 63,3\%.

Tabel 7. Hasil Uji Hipotesis

\begin{tabular}{c|c|c|c|c|c}
\hline & Hipotesis & $\begin{array}{c}\text { Original } \\
\text { Sample }\end{array}$ & T Statistics & P Values & Kesimpulan \\
\hline H1 & $\begin{array}{c}\text { Konteks Teknologi }-> \\
\text { Penggunaan Media Sosial }\end{array}$ & 0.036 & 0.323 & 0.747 & $\begin{array}{c}\text { Tidak } \\
\text { Signifikan }\end{array}$ \\
\hline H2 & $\begin{array}{c}\text { Konteks Lingkungan -> } \\
\text { Penggunaan Media Sosial }\end{array}$ & 0.706 & 4.697 & 0.000 & Signifikan \\
\hline H3 & $\begin{array}{c}\text { Konteks Organisasi-> } \\
\text { Penggunaan Media Sosial }\end{array}$ & 0.206 & 1.591 & 0.112 & $\begin{array}{c}\text { Tidak } \\
\text { Signifikan }\end{array}$ \\
\hline H4 & $\begin{array}{c}\text { Penggunaan Media Sosial } \\
->\text { Performa Bisnis }\end{array}$ & 0.938 & 30.937 & 0.000 & Signifikan \\
\hline
\end{tabular}

Berdasarkan uji hipotesis yang telah dilakukan maka hipotesis H1: Tidak Signifikan, yang berarti Konteks teknologi tidak memiliki pengaruh signifikan terhadap Penggunaan Media Sosial usaha, Bakery di Jakarta. dikarenakan nilai P-values sebesar 0,747>0,05. Nilai $p$-value 0,747 yang lebih besar dari batas yang telah ditentukan yaitu sebesar yaitu 0,05 , yang artinya dapat disimpulkan bahwa Konteks teknologi tidak memiliki pengaruh terhadap Penggunaan Media Sosial.

Selanjutnya hipotesis H2: dapat diterima, yang berarti Konteks Lingkungan memiliki pengaruh signifikan terhadap Penggunaan Media Sosial usaha, Bakery di Jakarta. Hasil penelitian ini sejalan dengan penelitian yang telah dilakukan sebelumnya oleh Köse dan Sert (2015) yang menyatakan bahwa terdapat pengaruh yang positif dan signifikan antara Konteks Lingkungan dengan Penggunaan Media Sosial. Efek dari konteks lingkungan pada media sosial adalah adanya penggunaan pendekatan, metode, atau teknologi yang memungkinkan pengguna mengalami komunikasi interaktif dan berbagai cara berbagi, berkreasi, dan juga bertukar informasi.

Selanjutnya hipotesis H3: Tidak Signifikan, yang berarti Konteks Organisasi tidak memiliki pengaruhsignifikan terhadap Penggunaan Media Sosial usaha, Bakery di Jakarta. dikarenakan 
nilai P-values sebesar 0,112>0,05. Nilai p-value 0,112 yang lebih besar dari batas yang telah ditentukan yaitu sebesar yaitu 0.05 , yang artinya dapat disimpulkan bahwa Konteks Organisasi tidak memiliki pengaruh terhadap Penggunaan Media Sosial.

Untuk hipotesis H4: dapat diterima, yang berarti Penggunaan Media Sosial memiliki pengaruh signifikan terhadap Performa Bisnis usaha, Bakery di Jakarta. Hasil penelitian ini sejalan dengan penelitian yang telah dilakukan sebelumnya oleh Hogan dan Strasburger (2018) yang menyatakan ada pengaruh yang positif dan signifikan antara Penggunaan Media Sosial dengan Performa Bisnis.

\section{KESIMPULAN}

Berdasarkan hasil dari pengolahan dan analisis data yang sudah dilakukan, maka kesimpulan dalam penelitian ini adalah sebagai berikut:

1. Tidak terdapat pengaruh Konteks teknologi terhadap Penggunaan Media Sosial

2. Terdapat pengaruh Konteks Lingkungan terhadap Penggunaan Media Sosial

3. Tidak terdapat pengaruh Konteks Organisasi terhadap Penggunaan Media Sosial

4. Terdapat pengaruh Penggunaan Media Sosial terhadap Performa Bisnis Usaha Bakery

\section{Saran}

Saran yang dapat disampaikan dari hasil penelitian ini adalah sebagai berikut:

a. Peneliti menyarankan agar penelitian selanjutnya dapat menambah jumlah responden memperluas jangkauan responden sehingga penelitian selanjutnya bisa mendapatkan hasil yang lebih mewakili.

b. Peneliti menyarankan kepada pengusaha usaha bakery agar bisa lebih memanfaatkan media sosial untuk mendapat pelanggan baru (terutama yang berusia muda), berbagai macam kegiatan promosi sehingga dapat meningkatkan performa usahanya.

\section{REFERENSI}

Akbar, Caesar. (2020). Ma'ruf Amin: Baru 13 Persen UMKM Pakai Teknologi Digital. Diakses dari: https://bisnis.tempo.co/read/1397627/maruf-amin-baru-13-persen-umkm-pakaiteknologi-digital/full\&view $=$ ok

Barney, J., (1991). Firm Resources and Sustained Competitive Advantage. Journal of Management, 17(1), 99-120.

Basole, R. C. (2005). Mobilizing the Enterprise: A Conceptual Model of Transformational Value and Enterprise Readiness. Makalah dipresentasikan pada Konferensi Nasional ASEM ke26. Virginia Beach, VA, Oktober 26-29.

Hogan, Marjorie dan Strasburger, Victor C. (2018). Social Media and New Technology: A Primer. International Journal of Educational Policies.

Köse, Utku dan Sert, Selçuk. (2015). Social Media Environments and Their Role on Success of Marketing Processes. Journal of Information Economy and Management. Volume: X Issue: II

Newswire. (2012). PELUANG USAHA: Pengusaha bakery ini laris berkat jejaring sosial. Diakses dari https://bandung.bisnis.com/read/20120424/550/968313/peluang-usahapengusaha-bakery-ini-laris-berkat-jejaring-sosial 
Osch, Wietske Van dan Coursaris, Constantinos. (2013) .Organizational Social Media: A Comprehensive Framework and Research Agenda. International Conference on System Sciences.

Rapali, J. A. dan Soelaiman, Lydiawati. (2019). Pengaruh Teknologi, Organisasi, Dan Lingkungan Eksternal Terhadap Kinerja Bisnis Umkm Di Jakarta Melalui Adopsi Media Sosial Sebagai Variabel Mediasi. Jurnal Manajerial dan Kewirausahaan, Volume I No. 4/2019 Hal: 890-899

Rusu, Gabriela and Avasilcai, Silvia. (2015). Organizational Context - Relationships with Human Resources Motivation and Work Performance. International Journal of Engineering and Management.

Soares-Aguiar, A. dan Palma-Dos-Reis, A. (2008). Why do firms adopt e-procurement systems? Using logistic regression to empirically test a conceptual model. IEEE Transactions on Engineering Management, Vol. 55, pp. 120-33.

Soelaiman, Lydiawati dan Utami, Anastasia Ria. 2021. "Faktor-Faktor yang Mempengaruhi Adopsi Media Sosial Instagram dan Dampaknya Terhadap Kinerja UMKM", Jurnal Muara Ilmu Ekonomi dan Bisnis, Vol. 5, No. 1, April 2021 : hal 124-133.

Tornatzky, L. G., dan M. Fleischer. (1990). The Process of Technological Innovation. Lexington. MA: Penerbit Lexington Books. 